Article

\title{
Study on the Product Characteristics of Pyrolysis Lignin with Calcium Salt Additives
}

\author{
Yong Cui ${ }^{1, *}$, Wenliang Wang ${ }^{2}$ and Jianmin Chang ${ }^{3}$ \\ 1 Precision Manufacturing Engineering Department, Suzhou Vocational Institute of Industrial Technology, \\ Suzhou 215104, China \\ 2 College of Bioresources Chemical and Materials Engineering, Shaanxi University of Science \& Technology, \\ Xi'an 710021, China; wangwenliang@sust.edu.cn \\ 3 College of Materials Science and Technology, Beijing Forestry University, Beijing 100083, China; \\ cjianmin@bjfu.edu.cn \\ * Correspondence: 00767@siit.edu.cn
}

Received: 2 April 2019; Accepted: 11 May 2019; Published: 16 May 2019

\begin{abstract}
This study investigated and compared the product characteristics of pyrolysis lignin under different catalytic effects resulting from various calcium salts. The pyrolysis of lignin was conducted in a fixed-bed reactor with calcium salt additives, which included $\mathrm{CaCl}_{2}, \mathrm{Ca}(\mathrm{OH})_{2}$, and $\mathrm{Ca}(\mathrm{HCOO})_{2}$. The compositions of gas and bio-oil were detected using gas chromatography/mass spectrometry (GC/MS). The characterizations of chars were examined using Brunauer-Emmett-Teller (BET) surface area and scanning electron microscopy (SEM). The results indicate that all three types of calcium salts helped to promote bio-oil yield and inhibit gas and char from forming. Regarding the composition of gas products, calcium salt additives increased the concentrations of $\mathrm{H}_{2}$ and $\mathrm{CH}_{4}$ while decreasing the concentration of $\mathrm{CO}$. In addition, calcium salt additives facilitated the formation of phenol and alkyl-phenols in bio-oil, but reduced the yields of guaiacol and vanillin, in the order $\mathrm{CaCl}_{2}<\mathrm{Ca}(\mathrm{OH})_{2}$ $<\mathrm{Ca}(\mathrm{HCOO})_{2}$. Furthermore, when compared with the addition of $\mathrm{CaCl}_{2}$, the chars prepared by the addition of $\mathrm{Ca}(\mathrm{OH})_{2}$ and $\mathrm{Ca}(\mathrm{HCOO})_{2}$ had relatively higher BET surface areas. In conclusion, $\mathrm{Ca}(\mathrm{HCOO})_{2}$ had the greatest positive influence in regard to the product quality of lignin pyrolysis whilst also elevating the yield of value-added chemicals in bio-oils.
\end{abstract}

Keywords: lignin; catalytic pyrolysis; bio-oil; calcium salt; product characteristics

\section{Introduction}

As the second most abundant component of lignocellulosic biomass, lignin is composed of hydroxyl phenylpropane units with 0-2 methoxyl group(s) which are linked through $\mathrm{C}-\mathrm{C}$ and ether bonds. Because lignin is the only renewable aromatic resource found in nature, the conversion of lignin to value-added chemicals is a very good method for alleviating the worldwide energy crisis. However, millions of tons of lignin are abandoned annually as industrial waste (especially in the forms of black liquor from pulp and paper mill) [1,2], which not only causes serious environmental pollution, but also results in huge bioresource waste. Therefore, it is important to develop renewable and alternative technologies for the effective use of lignin resources.

Regarding this, much attention has been paid to the thermal processes (mainly pyrolysis) involved in the production of fuels and aromatic chemicals from lignin, such as phenols $[3,4]$, aromatic hydrocarbons [5,6], and vanillin. Typically, catalytic pyrolysis was popularly regarded as a promising technical route to produce high-quality oil and gas [7-12]. Recently, many researchers have focused on lignin pyrolysis with calcium salt additives, which improves the quality of the resulting bio-oil. Zhou et al. (2015) [13] developed a simple pretreatment of lignin with $\mathrm{Ca}(\mathrm{OH})_{2}$ 
that made possible the continuous pyrolysis of lignin, thus producing a phenolic-rich bio-oil. They found that pretreatment with $\mathrm{Ca}(\mathrm{OH})_{2}$ reduced the melting and agglomeration behavior of lignin and promoted its depolymerization to phenolic monomers and dimers. Mukkamala et al. (2012) [14] showed that adding $\mathrm{Ca}(\mathrm{HCOO})_{2}$ to lignin before fast pyrolysis resulted in the deoxyhydrogenation of the lignin during pyrolysis. Wang et al. (2015) [15] investigated the effect of adding $\mathrm{CaCl}_{2}$ on the physicochemical properties of products from lignin pyrolysis and proved that the phenol content in bio-oil was significantly increased.

On the basis of these previous studies, it was revealed that adding calcium salt to lignin is an effective method for improving the quality of pyrolysis products. However, the influences of calcium salt on the physicochemical properties of pyrolysis products have so far not been fully clarified. Furthermore, the catalytic effects of different calcium salts have not been comprehensively compared. Consequently, the object of this article was to understand the catalytic effects of $\mathrm{CaCl}_{2}$, $\mathrm{Ca}(\mathrm{OH})_{2}$, and $\mathrm{Ca}(\mathrm{HCOO})_{2}$ on the physicochemical properties of gas, bio-oil, and char from lignin pyrolysis. In addition, the research results were expected to act as a fundamental study, demonstrating what value-added chemicals (mainly phenolic compounds) can potentially be obtained from lignin pyrolysis with these calcium salt additives. A fixed-bed reactor was used in this study, which has the advantages of a simple structure and flexible operation, compared with other pyrolysis reactors (fluidized beds, screw kilns, spouted beds, etc.). Gas chromatography/mass spectrometry (GC/MS), Brunauer-Emmett-Teller (BET), and scanning electron microscopy (SEM) methods were adopted to investigate the product characteristics of pyrolysis lignin with calcium salt additive.

\section{Material and Methods}

\subsection{Material Preparation}

The lignin was purchased from Tokyo Chemical Industry Co., Ltd (Tokyo, Japan), which was extracted from larch through the kraft process. According to Chinese Standards GB/T 17664-1999, the proximate analysis of the air-dried lignin was $66.43 \mathrm{wt} . \%$ volatile and moisture, $6.21 \mathrm{wt} . \%$ ash, and $27.36 \mathrm{wt} . \%$ fixed carbon. The elemental composition of the air-dried alkali lignin was $62.4 \mathrm{wt} . \%$ carbon, $6.14 \mathrm{wt.} \%$ hydrogen, $29.43 \mathrm{wt} . \%$ oxygen, $0.26 \mathrm{wt} . \%$ nitrogen, and $1.77 \mathrm{wt} . \%$ sulfur, which were determined by Elementar Vario EL elemental analyzer (Elementar, Shanghai, China).

Three kinds of calcium additives, including $\mathrm{CaCl}_{2}, \mathrm{Ca}(\mathrm{OH})_{2}$, and $\mathrm{Ca}(\mathrm{HCOO})_{2}$, were selected to investigate the effect on lignin pyrolysis. On the basis of the mass ratio of 1:20 between the Ca metal atom and the lignin, it was calculated that additive amounts of $\mathrm{CaCl}_{2}, \mathrm{Ca}(\mathrm{OH})_{2}$, and $\mathrm{Ca}(\mathrm{HCOO})_{2}$ were $13.9 \%, 9.3 \%$ and $16.3 \%$ in the lignin, respectively. The excessive impregnation method was used to add calcium salts, which were dissolved in the deionized water. The lignin was impregnated with the additive solutions by ultrasonic immersing for $0.5 \mathrm{~h}$ and static immersion for $12 \mathrm{~h}$. Finally, the absorbed water in the lignin was removed by vacuum drying at $105^{\circ} \mathrm{C}$ for $6 \mathrm{~h}$, and then the test samples were obtained.

\subsection{Experimental Methods}

Pyrolysis experiments were all carried out in the fixed-bed reactor (shown in Figure 1), which heated a certain amount of the tested sample $(5 \mathrm{~g})$ from ambient temperature to $600{ }^{\circ} \mathrm{C}$ at a heating rate of $20^{\circ} \mathrm{C} / \mathrm{min}$ by microwave $(1000 \mathrm{~W})$, where it was kept constant for $25 \mathrm{~min}$ [16]. Nitrogen with a flow of $1200 \mathrm{~mL} \mathrm{~min}{ }^{-1}$ was used as the carrier gas. The produced pyrolysis vapors firstly passed through the condensing system with a collector to obtain liquid products (bio-oil). The uncondensed gas cleaned by the filter was stored in vacuum bags for analysis. Finally, the test samples were fully pyrolyzed and the heating temperature started to drop, but the nitrogen was still supplied to avoid oxidation until the pyrolysis residues (chars) had cooled down to room temperature. The quantity of the generated bio-oil and char was weighed, while the mass of uncondensed gas was measured by the weight difference. The water content in the bio-oil was determined with Karl Fischer Moisture Meter 
(ZDJ-1S, Hengteya, Taizhou, Jiangsu, China), which selected Karl reagent as the standard solution and methanol as the titrating solvent. Each test was repeated at least three times under the same conditions, and their average values were calculated and used.

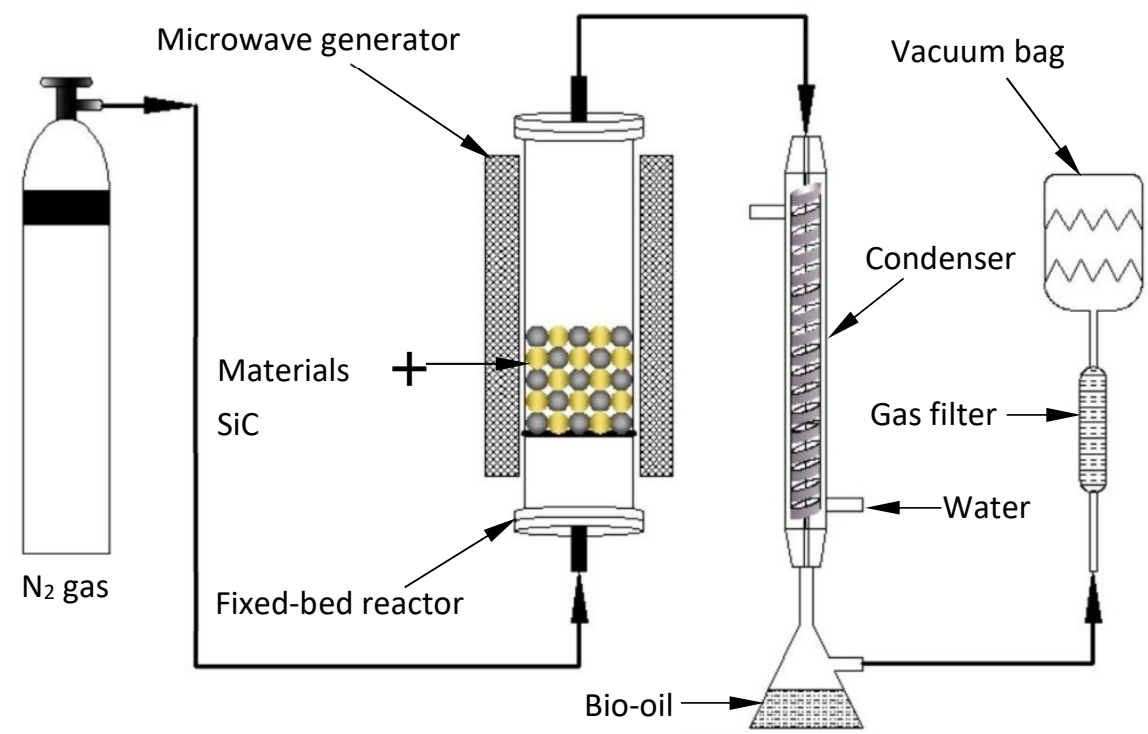

Figure 1. Schematic diagram of pyrolysis reactor.

A micro-chromatograph (Agilent 4900, Santa Clara, CA, USA) was used to measure the composition of non-condensable pyrolysis gas. In order to achieve a good separation of $\mathrm{H}_{2}, \mathrm{CH}_{4}, \mathrm{CO}$, and $\mathrm{CO}_{2}$, two specific capillary columns (Molecular sieve 5A, Plot $\mathrm{U}$ ) were also equipped. The temperature in the inlet was kept at $100{ }^{\circ} \mathrm{C}$ while temperatures within the two columns were kept at $55^{\circ} \mathrm{C}$ and $80{ }^{\circ} \mathrm{C}$, respectively [17].

A GC/MS (Shimadzu GCMS-QP2010Plus, Shimadzu, Kyoto, Japan) was applied to identify detailed composition of the bio-oil. With a He gas flow rate of $1.0 \mathrm{~mL} \mathrm{~min}^{-1}$ in a split-flow ratio of $30: 1$, the temperature inside the inlet was kept at $280^{\circ} \mathrm{C}$. Heating temperatures were scheduled as follows: The temperatures were kept at $50{ }^{\circ} \mathrm{C}$ for $5 \mathrm{~min}$, then maintained at $280{ }^{\circ} \mathrm{C}$ for $15 \mathrm{~min}$ as the temperature increased at a rate of $5^{\circ} \mathrm{C} \mathrm{min}^{-1}$. Junction and ion temperatures were kept at $280{ }^{\circ} \mathrm{C}$ and $250^{\circ} \mathrm{C}$, respectively, operating in an EI source electron energy of $70 \mathrm{eV}$ and a scan range of $20-400 \mu$ for mass spectrometry (MS).

The nitrogen adsorption (Quadrasorb SI, Boynton Beach, FL, USA) analyzed specific surface areas of chars obtained from lignin pyrolysis. Using the BET method, the surface area was calculated after each sample was outgassed at $77 \mathrm{~K}$ for $3 \mathrm{~h}$. An SEM (Hitachi S-3400N, Hitachi, Tokyo, Japan) also examined the surface morphology of the chars. Before testing, all the char samples were washed with alcohol solution and later dried at $120^{\circ} \mathrm{C}$.

\section{Results and Discussion}

\subsection{The Yields of Pyrolysis Products}

As shown in Figure 2a, the pyrolysis of lignin with and without calcium additives resulted in a high char production, which was due to some very stable aromatic rings and high carbon content in the lignin $[18,19]$. In this study, the yields of bio-oil, gas, and char for raw lignin pyrolysis were in agreement with the results of many reports in the literature $[20,21]$. Figure 2a shows that the catalytic effect of three calcium salt additives led to the same tendencies in the yields of pyrolysis products, which promoted the bio-oil yields and inhibited the formation of gas and char. The influences of the three additives on product distribution were consistent with previous studies. Wang (2015) [21] proved that the catalytic pyrolysis of lignin using calcium chloride resulted in a decrease in residual 
carbon formation and an increase in bio-oil yield. Peng (2014) [17] reported that liquid yield increased when hydroxide alkalis was added in lignin pyrolysis, but the yields of char and gas decreased. Mukkamala (2012) [14] found that adding calcium formate to lignin during fast pyrolysis promoted the deoxyhydrogenation reaction and enhanced the liquid yield.

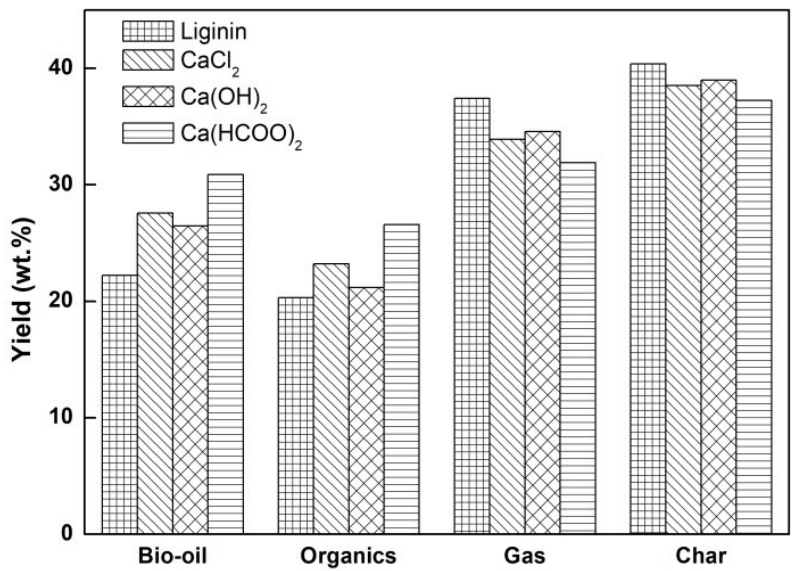

(a)

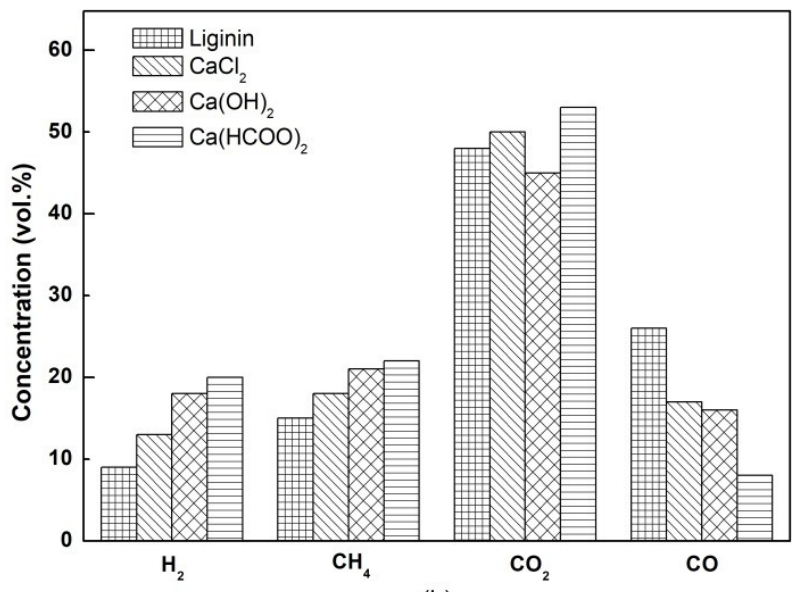

(b)

Figure 2. (a) Product yields and (b) gas composition in the pyrolysis of lignin with and without calcium salt additives.

Figure $2 \mathrm{~b}$ compares the gas composition obtained from pure lignin pyrolysis and that obtained in the catalyzed pyrolysis with calcium salt. As observed, the gas fraction was mainly composed of $\mathrm{CO}_{2}$, with a lower contribution of $\mathrm{CO}, \mathrm{H}_{2}$, and $\mathrm{CH}_{4}$. The results in Figure $2 \mathrm{~b}$ revealed that all of the calcium salt additives increased the concentrations of $\mathrm{H}_{2}$ and $\mathrm{CH}_{4}$ when compared with those corresponding to the pyrolysis of pure lignin, but decreased the concentrations of $\mathrm{CO}$. According to previous studies, the generation of $\mathrm{H}_{2}$ results from the rearrangement of the Aromatic rings to form a more organized structure [22], while the releasing of $\mathrm{CO}_{2}, \mathrm{CO}$, and $\mathrm{CH}_{4}$ are attributable to the fragmentation of the propyl chains and the substitution of the methoxyl groups of the aromatic rings [23,24]. From the higher $\mathrm{H}_{2}$ and $\mathrm{CH}_{4}$ contents in the gas, it can be deduced that cracking of lignin into small-molecule gases was enhanced in the pyrolysis process due to the catalytic effect of the calcium salt additives. Furthermore, the lower $\mathrm{CO}$ content indicates that the calcium salts were active in a water-gas shift reaction, which can convert the $\mathrm{CO}$ into $\mathrm{CO}_{2}$ and $\mathrm{H}_{2}$ [25]. Of course, this reaction can also contribute to the higher $\mathrm{H}_{2}$ and $\mathrm{CO}_{2}$ content in the gaseous fraction. In addition, $\mathrm{Ca}(\mathrm{HCOO})_{2}$ can lead to the production of $\mathrm{H}_{2}$ and $\mathrm{CO}_{2}$ due to thermal decomposition at high pyrolysis temperatures. The reduced gas volume of $\mathrm{CO}_{2}$ in the case of $\mathrm{Ca}(\mathrm{OH})_{2}$ could be related to absorption by alkalis. 


\subsection{The Chemical Composition of Bio-Oil}

The compositions of bio-oil from pyrolyzing lignin with and without the additives of $\mathrm{CaCl}_{2}$, $\mathrm{Ca}(\mathrm{OH})_{2}$, and $\mathrm{Ca}(\mathrm{HCOO})_{2}$ were analyzed using GC/MS. A total of five categories (including 46 kinds of compounds) were detected in this experiment, as detailed in Table 1. As seen in Figure 3a, the bio-oils of all lignin samples were mainly composed of phenols, with aldehydes, ketones, ethers, and aromatic hydrocarbons also being present. It is well known that phenolic compounds are the major products from lignin pyrolysis [26-28], which are derived from the cleavage of the ether bonds between the lignin-building units and the further cracking or replacing of the side chains of these units [29]. As compared to pyrolysis without a catalyst, adding calcium salts dramatically increased the content of phenols in the bio-oils, from $73.65 \%$ to $78.03 \%, 79.29 \%$ and $79.86 \%$, respectively. Therefore, it is obvious that all these additives had a significant catalytic effect on the phenol yield in lignin pyrolysis; this effect was more pronounced with $\mathrm{Ca}(\mathrm{HCOO})_{2}$ additives. Moreover, one can see that the additions of $\mathrm{Ca}(\mathrm{OH})_{2}$ and $\mathrm{Ca}(\mathrm{HCOO})_{2}$ generally decreased the productions of aldehydes and ketones, which were obtained from the $\mathrm{C}-\mathrm{C}$ cleavage in the alkyl side chains with the $-\mathrm{CH}_{2} \mathrm{OH}$ or $-\mathrm{COOH}$ groups $[30,31]$. Consequently, it is supposed that the catalytic effect of calcium salts could reduce the unsaturated degree of the liquid products from lignin pyrolysis. Besides, the formation of ethers and aromatic hydrocarbons was attributed to the cracking of the ether and methoxy linkages in the alkyl side chains and to the changes in substitution pattern of the aromatic rings [22,29]. Both $\mathrm{CaCl}_{2}$ and $\mathrm{Ca}(\mathrm{HCOO})_{2}$ increased the production of aromatic hydrocarbons and decreased that of ethers, whereas calcium formate facilitated more of an increase in the production of aromatic hydrocarbons (from $1.96 \%$ to $8.73 \%$ ) and a decrease in the production of ethers (from $16.35 \%$ to $7.56 \%$ ).

Table 1. The major compositions of bio-oil from lignin pyrolysis with and without calcium salt additives.

\begin{tabular}{|c|c|c|c|c|c|}
\hline \multirow{2}{*}{ No. } & \multirow{2}{*}{ Name of Compounds } & \multicolumn{4}{|c|}{ Relative Content (Area\%) } \\
\hline & & Lignin & $\mathrm{CaCl}_{2}$ & $\mathrm{Ca}(\mathrm{OH})_{2}$ & $\mathrm{Ca}(\mathrm{HCOO})_{2}$ \\
\hline & Phenols & 73.65 & 78.03 & 79.29 & 79.86 \\
\hline 1 & Phenol & 3.08 & 4.39 & 6.25 & 14.89 \\
\hline 2 & 2-Methylphenol & 0.82 & 1.98 & 2.19 & 3.22 \\
\hline 3 & 4-Methylphenol & 0.34 & 1.18 & 1.81 & 3.36 \\
\hline 4 & Guaiacol & 26.1 & 21.63 & 20.04 & 17.68 \\
\hline 5 & 2,4-Xylenol & - & 0.56 & 1.09 & 0.98 \\
\hline 6 & 2,6-Xylenol & - & - & 0.71 & 1.48 \\
\hline 7 & 2-Ethylphenol & 0.78 & 0.97 & 1.3 & 1.61 \\
\hline 8 & 4-Ethylphenol & 0.21 & 5.34 & 5.78 & 7.43 \\
\hline 9 & 4-Ethyl-2-methylphenol & 0.67 & 1.98 & 3.22 & 3.01 \\
\hline 10 & 2-Methoxy-5-methylphenol & 5.93 & 5.05 & 5.68 & 4.96 \\
\hline 11 & 2-Methoxy-4-methylphenol & 9.27 & 9.68 & 7.67 & 2.13 \\
\hline 12 & 3-Methylcatechol & 1.25 & 2.18 & 2.04 & 3.89 \\
\hline 13 & 3-Methoxycatechol & 1.02 & 0.89 & 0.98 & 0.52 \\
\hline 14 & 2-Methoxy-4-ethylphenol & 3.55 & 4.87 & 5.53 & 3.73 \\
\hline 15 & 2,6-Xylohydroquinone & - & 0.61 & 0.78 & 0.68 \\
\hline 16 & 4-Hydroxy-3-methylacetophenone & 2.37 & 3.08 & 2.1 & 1.79 \\
\hline 17 & 2,6-Dimethoxyphenol & 5.48 & 2.83 & 2.62 & 2.01 \\
\hline 18 & 3-Allyl-2-methoxyphenol & - & 0.79 & 1.58 & 0.95 \\
\hline 19 & 2-Methoxy-4-propylphenol & - & 0.67 & 0.89 & 0.73 \\
\hline 20 & Vanillin & 1.79 & 1.05 & 0.76 & 0.62 \\
\hline 21 & 2-Methoxy-4-propenylphenol & 1.04 & 0.79 & 1.73 & 0.46 \\
\hline 22 & cis-Isoeugenol & - & 2.05 & - & 0.19 \\
\hline 23 & Guaiacylacetone & - & 1.22 & 0.49 & 0.74 \\
\hline 24 & Apocynin & 1.04 & 2.91 & 1.43 & 1.71 \\
\hline 25 & Homovanillic acid & 0.57 & 1.02 & 0.47 & 1.09 \\
\hline 26 & Salicylaldehyde & - & 0.31 & 1.03 & - \\
\hline 27 & Isovanillin & 8.34 & - & 1.12 & - \\
\hline
\end{tabular}


Table 1. Cont.

\begin{tabular}{|c|c|c|c|c|c|}
\hline \multirow{2}{*}{ No. } & \multirow{2}{*}{ Name of Compounds } & \multicolumn{4}{|c|}{ Relative Content (Area\%) } \\
\hline & & Lignin & $\mathrm{CaCl}_{2}$ & $\mathrm{Ca}(\mathrm{OH})_{2}$ & $\mathrm{Ca}(\mathrm{HCOO})_{2}$ \\
\hline & Aldehydes & 3.82 & 6.02 & 3.09 & 1.53 \\
\hline \multirow[t]{2}{*}{1} & Veratraldehyde & 3.82 & 6.02 & 3.09 & 1.53 \\
\hline & Ketones & 4.22 & 4.78 & 2.01 & 2.32 \\
\hline 1 & Acetone & 1.02 & 2.76 & - & - \\
\hline 2 & 3-Ethyl-2-hydroxy-2-cyclopenten-1-one & - & 2.02 & - & - \\
\hline 3 & 2-Methyl-2-cyclopentenone & 1.08 & - & 2.01 & 0.92 \\
\hline 4 & 3-Methyl-2-cyclopentenone & 2.12 & - & - & 0.78 \\
\hline \multirow[t]{2}{*}{5} & Methycyclopentenolone & - & - & - & 0.62 \\
\hline & Ethers & 16.35 & 8.61 & 14.19 & 7.56 \\
\hline 1 & 4-Methoxystyrene & 1.62 & - & 2.08 & 1.21 \\
\hline 2 & 4-Methylanisole & 0.36 & - & 0.8 & 0.86 \\
\hline 3 & Veratrole & 9.02 & 4.22 & 8.2 & 2.45 \\
\hline 4 & 4-Ethylveratrol & 3.81 & 2.92 & 1.08 & 2.03 \\
\hline 5 & 4-Ethyl-1,2-dimethoxybenzene & - & 0.97 & 1.64 & 1.01 \\
\hline \multirow[t]{2}{*}{6} & Methylisoeugenol & 1.54 & 0.5 & 0.39 & - \\
\hline & Aromatic Hydrocarbons & 1.96 & 2.56 & 1.42 & 8.73 \\
\hline 1 & Toluene & - & 1.21 & 0.87 & 2.63 \\
\hline 2 & Benzene & - & 0.18 & - & 0.32 \\
\hline 3 & 2-Isopropyltoluene & 0.41 & 1.03 & - & 2.22 \\
\hline 4 & 3-Isopropyltoluene & 0.22 & - & 0.55 & 2.23 \\
\hline 5 & Naphthalene & 0.81 & - & - & 0.21 \\
\hline 6 & Anthracene & 0.52 & 0.14 & - & - \\
\hline 7 & 2,4-Dimethyl styrene & - & - & - & 1.12 \\
\hline
\end{tabular}

Figure $3 \mathrm{~b}$ shows the variation in contents of major phenols from pyrolyzing lignin with and without calcium salt additives. The major phenols were phenol, alkyl-phenols (e.g., methylphenol, ethylphenol, and xylenol), methoxy-phenols (e.g., methoxy-methylphenol, methoxy-ethylphenol, methoxy-propylphenol, and methoxy-propenylphenol), guaiacol, and vanillin. From Figure $3 \mathrm{~b}$ and Table 1, it can be seen that calcium salt additives greatly elevated the production of phenol and alkyl-phenols, and the $\mathrm{Ca}(\mathrm{HCOO})_{2}$ additive caused the largest increase in the formation of these two chemicals (14.89\% for phenol and $21.09 \%$ for alkyl-phenols). The result implies that these additives promoted the cracking of lignin into monophenols, which was beneficial to improve the chemical reactivity of bio-oil. Furthermore, one can also see that all the additives in this experiment tended to decrease the productions of guaiacol and vanillin in an order $\mathrm{CaCl}_{2}<\mathrm{Ca}(\mathrm{OH})_{2}<\mathrm{Ca}(\mathrm{HCOO})_{2}$, the yields of which were originally about $26.1 \%$ and $1.79 \%$, respectively, in the bio-oils of pure lignin pyrolysis. This indicates that calcium salts facilitated the decomposition reactions of substances with a guaiacyl phenol structure such as guaiacol and vanillin. According to Hosoya (2008) [32], lignin-derived compounds can undergo secondary reactions at high temperatures. Therefore, this led us to the conclusion that adding calcium salts promoted secondary reactions in the pyrolysis process of lignin, which is in line with the theory that guaiacyl phenols tend to decompose to monophenols. Regarding the methoxy-phenols content, the addition of $\mathrm{CaCl}_{2}$ and $\mathrm{Ca}(\mathrm{OH})_{2}$ slightly increased it by a few percent compared to its production (19.79\%) in lignin pyrolysis, while $\mathrm{Ca}(\mathrm{HCOO})_{2}$ effectively reduced it to $12.01 \%$. Figure 3 also demonstrates that $\mathrm{Ca}(\mathrm{HCOO})_{2}$ was more influential than the same amount of $\mathrm{CaCl}_{2}$ or $\mathrm{Ca}(\mathrm{OH})_{2}$ on facilitating the production of value-added chemicals (e.g., phenol, alkyl-phenols, and aromatic hydrocarbons) in bio-oils from lignin pyrolysis. On the basis of former researches [14,33], when adding modest amounts of formic acid in the form of a metal salt, deoxygenation, addition, and reduction reactions are promoted during fast pyrolysis of lignin, facilitated by the hydrogen generated 
from the thermal decomposition of the formate. In addition, this is in good agreement with the results of this study: That catalysis of calcium formate is more conducive to reducing the oxygen content and increasing the saturated degree of the products of lignin pyrolysis.

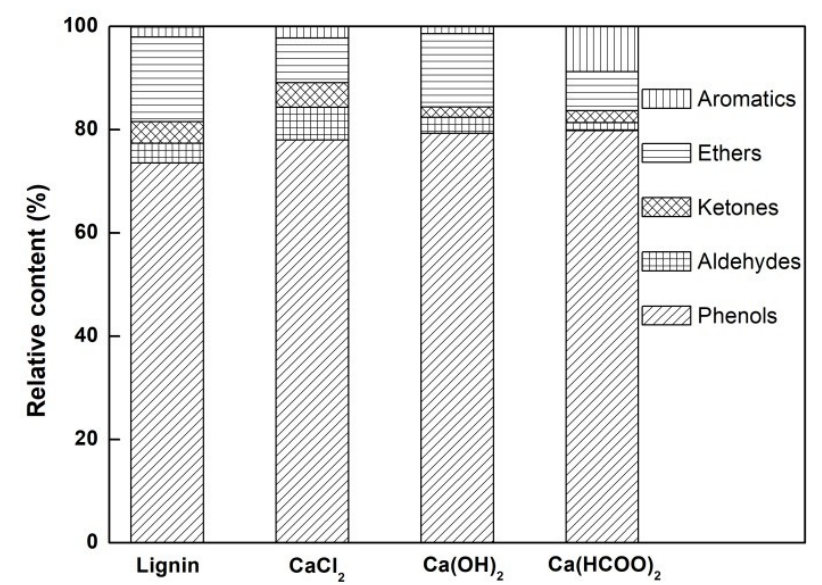

(a)

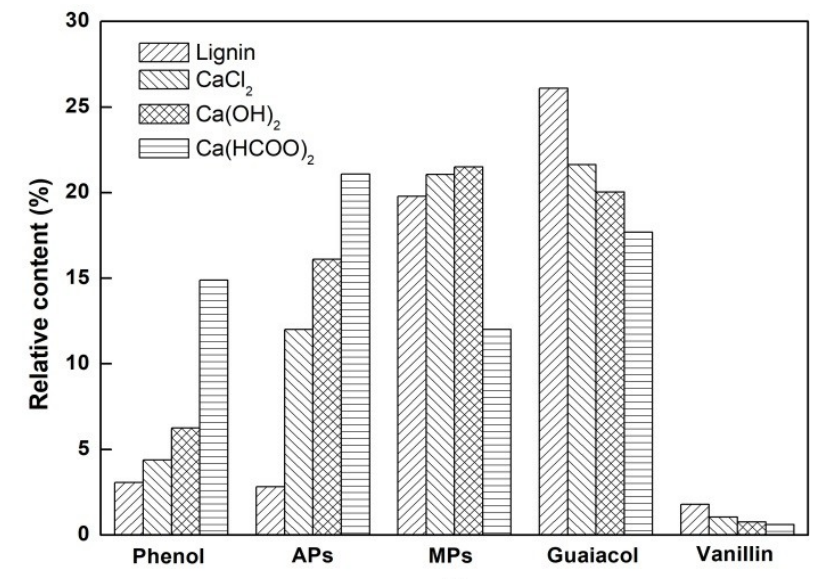

(b)

Figure 3. (a) Bio-oil composition and (b) contents of major phenols in the pyrolysis of lignin with and without calcium salt additives. APs: Alkyl-phenols, MPs: Methoxy-phenols.

\subsection{The Characteristics of Char}

As seen in Figure 4, all the samples exhibited a weak absorption in the entire relative pressure range, which demonstrates that there was a relatively small number of micropores and mesoporous in the pyrolysis chars. The lower values of BET surface area and total pore volume (in Table 2) also illustrates that the chars obtained from lignin pyrolysis with or without additives were almost non-porous materials. This, therefore, well coincides with the previous conclusion that chars derived from lignin pyrolysis need the process of further activation before being used as commercial activated carbons [21]. Furthermore, according to IUPAC (International Union of Pure and Applied Chemistry) classification, the diameter of mesopores was between 2 and $50 \mathrm{~nm}$ [34]. Thus, the chars (prepared in this experiment) showed the character of mesoporosity, depending on the value of average pore diameter listed in Table 2. 


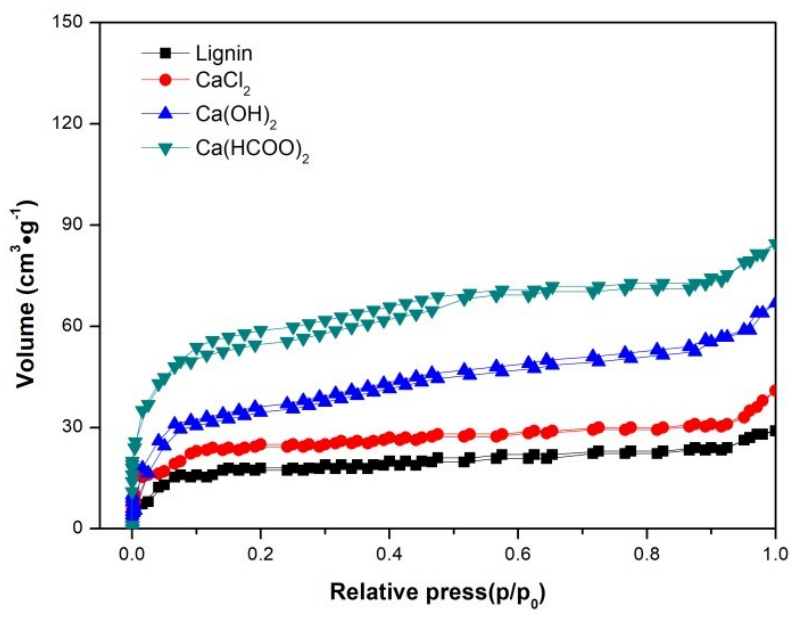

Figure 4. $\mathrm{N}_{2}$ adsorption-desorption isotherm of chars from lignin pyrolysis with and without calcium salt additives.

Table 2. The specific surface area and pore structure of chars from lignin pyrolysis with and without calcium salt additives.

\begin{tabular}{|c|c|c|c|}
\hline Samples & $\begin{array}{c}S_{B E T} \\
\left(\mathrm{~m}^{2} \cdot \mathrm{g}^{-1}\right)\end{array}$ & $\begin{array}{l}\text { Total Pore Volume } \\
\quad\left(\mathrm{cm}^{3} \cdot \mathrm{g}^{-1}\right)\end{array}$ & $\begin{array}{l}\text { Average Pore Diameter } \\
\text { (nm) }\end{array}$ \\
\hline Lignin & 40.62 & 0.035 & 3.078 \\
\hline $\mathrm{CaCl}_{2}$ & 62.16 & 0.051 & 3.091 \\
\hline $\mathrm{Ca}(\mathrm{OH})_{2}$ & 135.68 & 0.115 & 3.012 \\
\hline $\mathrm{Ca}(\mathrm{HCOO})_{2}$ & 175.31 & 0.152 & 3.005 \\
\hline
\end{tabular}

One can also see that chars prepared by lignin pyrolysis with the addition of $\mathrm{Ca}(\mathrm{OH})_{2}$ and $\mathrm{Ca}(\mathrm{HCOO})_{2}$ had a greater amount of $\mathrm{N}_{2}$ absorption, a higher BET surface area, and total pore volume compared to two other kinds of chars in this study. It was seen that adding $\mathrm{Ca}(\mathrm{OH})_{2}$ or $\mathrm{Ca}(\mathrm{HCOO})_{2}$ during lignin pyrolysis was conducive to improving the adsorption of the obtained chars. As a kind of hydroxide, $\mathrm{Ca}(\mathrm{OH})_{2}$ may play the role of chemical activating agent during the carbonization process of lignin, causing more pores in the chars to be created or enlarged. Additionally, the formate was easily decomposed to volatile substances (such as $\mathrm{H}_{2}$ and $\mathrm{CO}_{2}$ ) at high temperatures, which can promote the formation of pore structures and enhance the BET surface area of the char from the lignin pyrolysis.

As shown in Figure 5a, the surface of the char obtained from pure lignin pyrolysis was relatively smooth and had no obvious pores. Hence, that kind of char needed further activation to improve the capacity of absorption. As can be seen in Figure 5b, a large amount of particulate matter was attached to the surface of chars and fewer pores were discovered, which indicates that the added $\mathrm{CaCl}_{2}$ still remained after the pyrolysis process and blocked the incipient porosity of the chars. However, the surface was obviously unsmooth in the samples in which $\mathrm{Ca}(\mathrm{OH})_{2}$ and $\mathrm{Ca}(\mathrm{HCOO})_{2}$ was added, as can be seen in Figure 5c,d. Particularly, more pores were seen in the char produced from the addition of $\mathrm{Ca}(\mathrm{HCOO})_{2}$. 

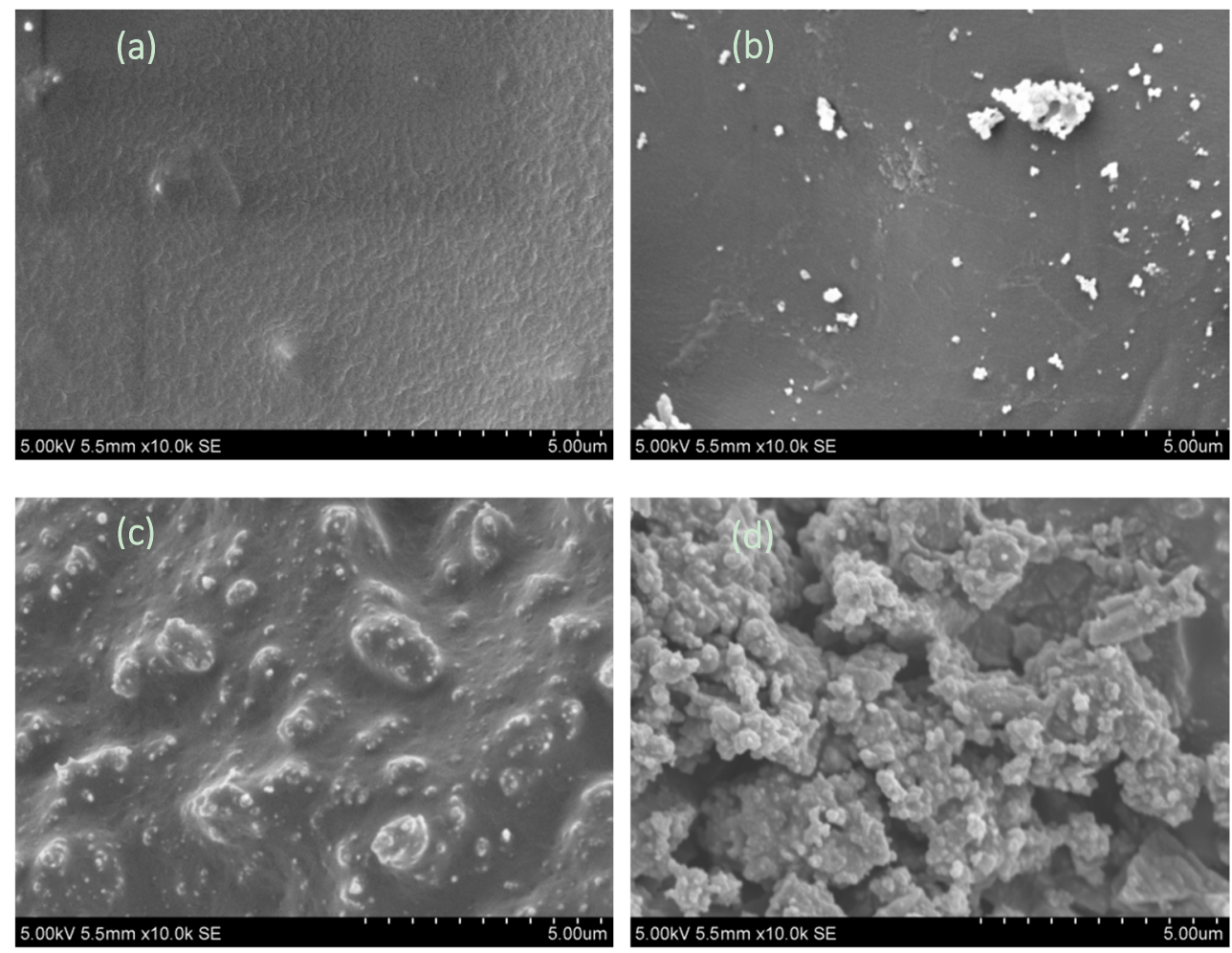

Figure 5. Scanning electron microscopy (SEM) images of chars prepared from (a) pure lignin pyrolysis or with the additions of $(\mathbf{b}) \mathrm{CaCl}_{2},(\mathbf{c}) \mathrm{Ca}(\mathrm{OH})_{2}$, and (d) $\mathrm{Ca}(\mathrm{HCOO})_{2}$.

\section{Conclusions}

The catalytic effects of calcium salt additives on the product characteristics of pyrolysis lignin were experimentally investigated and compared. The results show that the catalytic effect of three kinds of calcium salt additives led to the same tendencies in the yields of pyrolysis products, which promoted the bio-oil yields and inhibited the formation of gas and char. Regarding the gas formed through lignin pyrolysis, calcium salt additives increased the concentrations of $\mathrm{H}_{2}$ and $\mathrm{CH}_{4}$, but decreased the concentrations of $\mathrm{CO}$. The chemicals in bio-oil from pyrolyzing lignin with or without additives mainly consisted of phenolic compounds, while calcium salt additives elevated the production of both phenol and alkyl-phenols and decreased the yields of guaiacol and vanillin in an order of $\mathrm{CaCl}_{2}<\mathrm{Ca}(\mathrm{OH})_{2}<\mathrm{Ca}(\mathrm{HCOO})_{2}$. Furthermore, adding $\mathrm{Ca}(\mathrm{OH})_{2}$ or $\mathrm{Ca}(\mathrm{HCOO})_{2}$ was more conducive to an increase in the adsorption of chars obtained from lignin pyrolysis. By comparing the catalytic effect of the additives used in this study, it can be seen that adding $\mathrm{Ca}(\mathrm{HCOO})_{2}$ in lignin pyrolysis is an effective method to improve the quality of the pyrolysis products and increase the content of value-added chemicals (e.g., phenol, alkyl-phenols, and aromatic hydrocarbons ) in bio-oils.

Author Contributions: W.W. developed the original idea; Y.C. designed and performed the experiments, analyzed the data and prepared the manuscript; J.C. edited the English writing.

Funding: This work was supported by the Natural Science Foundation of the Jiangsu Higher Education Institutions of China (18KJB480007), the Doctoral Scientific Research Foundation of Suzhou Vocational Institute of Industrial Technology (2019KYQD009), the Top-Notch Academic Programs Project of Jiangsu Higher Education Institutions (PPZY2015B186), the National Natural Science Foundation of China (31800497), the Key Laboratory of Suzhou (SZS201815).

Conflicts of Interest: The authors declare no conflicts of interest. 


\section{References}

1. Gao, Y.; Yue, Q.; Gao, B.; Sun, Y.; Wang, W.; Li, Q.; Wang, Y. Preparation of high surface area-activated carbon from lignin of papermaking black liquor by $\mathrm{KOH}$ activation for $\mathrm{Ni}(\mathrm{II})$ adsorption. Chem. Eng. J. 2013, 217, 345-353. [CrossRef]

2. Zhang, M.; Resende, F.L.P.; Moutsoglou, A. Catalytic fast pyrolysis of aspen lignin via Py-GC/MS. Fuel 2014, 116, 358-369. [CrossRef]

3. Jeon, M.J.; Jeon, J.K.; Suh, D.J.; Park, S.H.; Sa, Y.J.; Joo, S.H.; Park, Y.-K. Catalytic pyrolysis of biomass components over mesoporous catalysts using Py-GC/MS. Catal. Today 2013, 204, 170-178. [CrossRef]

4. De Wild, P.; Van der Laan, R.; Kloekhorst, A.; Heeres, E. Lignin Valorisation for Chemicals and (Transportation) Fuels via (Catalytic) Pyrolysis and Hydrodeoxygenation. Environ. Prog. Sustain. Energy 2010, 28, 461-469. [CrossRef]

5. Stephanidis, S.; Nitsos, C.; Kalogiannis, K.; Iliopoulou, E.F.; Lappas, A.A.; Triantafyllidis, K.S. Catalytic upgrading of lignocellulosic biomass pyrolysis vapours: Effect of hydrothermal pre-treatment of biomass. Catal. Today 2011, 167, 37-45. [CrossRef]

6. French, R.; Czernik, S. Catalytic pyrolysis of biomass for biofuels production. Fuel Process. Technol. 2010, 91, 25-32. [CrossRef]

7. Pütün, E. Catalytic pyrolysis of biomass: Effects of pyrolysis temperature, sweeping gas flow rate and $\mathrm{MgO}$ catalyst. Energy 2010, 35, 2761-2766. [CrossRef]

8. Zhou, L.; Yang, H.; Wu, H.; Wang, M.; Cheng, D. Catalytic pyrolysis of rice husk by mixing with zinc oxide: Characterization of bio-oil and its rheological behavior. Fuel Process. Technol. 2013, 106, 385-391. [CrossRef]

9. Zhang, X.; Liu, Q.; Zhang, Q.; Liu, Q.; Chen, L.; Li, Y.; Wang, C.; Ma, L. Aromatic fuel production from phenolics by catalytic hydrodeoxygenation over novel mo-based catalyst. Energy Procedia 2019, 158, 984-990. [CrossRef]

10. Hossein, J.; Agblevor, F.A. Hydrodeoxygenation of aqueous phase catalytic pyrolysis oil to liquid hydrocarbons using multi-functional nickel catalyst. Ind. Eng. Chem. Res. 2018, 57, 13257-13268.

11. Yuan, R.; Yu, S.L.; Shen, Y.F. Pyrolysis and combustion kinetics of lignocellulosic biomass pellets with calcium-rich wastes from agro-forestry residues. Waste Manag. 2019, 87, 86-96. [CrossRef]

12. Veksha, A.; Giannis, A.; Oh, W.D.; Lisak, G. Catalytic processing of non-condensable pyrolysis gas from plastics: Effects of calcium supports on nickel-catalyzed decomposition of hydrocarbons and $\mathrm{HCl}$ sorption. Chem. Eng. Sci. 2018, 189, 311-319. [CrossRef]

13. Zhou, S.; Brown, R.C.; Bai, X.L. The use of calcium hydroxide pretreatment to overcome agglomeration of technical lignin during fast pyrolysis. Green Chem. 2015, 17, 4748-4759. [CrossRef]

14. Mukkamala, S.; Wheeler, M.C.; van Heiningen, A.R.; DeSisto, W.J. Formate-Assisted Fast Pyrolysis of Lignin. Energy Fuels 2012, 26, 1380-1384. [CrossRef]

15. Wang, W.L.; Ren, X.Y.; Li, L.F.; Chang, J.M.; Cai, L.P.; Geng, J. Catalytic effect of metal chlorides on analytical pyrolysis of alkali lignin. Fuel Process. Technol. 2015, 134, 345-351. [CrossRef]

16. Wang, W.L.; Yu, Y.X.; Chang, J.M.; Bai, T.T. Comparative analysis of micro-crystal structures and bio-oil from pyrolysis of two barks. J. Fuel Chem. Technol. 2013, 41, 1310-1315.

17. Peng, C.; Zhang, G.; Yue, J.; Xu, G. Pyrolysis of lignin for phenols with alkaline additive. Fuel Process. Technol. 2014, 124, 212-221. [CrossRef]

18. Hosoya, T.; Kawamoto, H.; Saka, S. Pyrolysis behaviors of wood and its constituent polymers at gasification temperature. J. Anal. Appl. Pyrolysis 2007, 78, 328-336. [CrossRef]

19. Raveendran, K.; Ganesh, A.; Khilar, K.C. Pyrolysis characteristics of biomass and biomass components. Fuel 1996, 75, 987-998. [CrossRef]

20. Nowakowski, D.J.; Bridgwater, A.V.; Elliott, D.C.; Meier, D.; de Wild, P. Lignin fast pyrolysis: Results from an international collaboration. J. Anal. Appl. Pyrolysis 2010, 88, 53-72. [CrossRef]

21. Wang, W.L.; Ren, X.Y.; Chang, J.M.; Cai, L.P.; Shi, S.Q. Characterization of bio-oils and bio-chars obtained from the catalytic pyrolysis of alkali lignin with metal chlorides. Fuel Process. Technol. 2015, 138, 605-611. [CrossRef]

22. Collard, F.X.; Blin, J.; Bensakhria, A.; Valette, J. Influence of impregnated metal on the pyrolysis conversion of biomass constituents. J. Anal. Appl. Pyrolysis 2012, 95, 213-226. [CrossRef] 
23. López, M.B.; Blanco, C.G.; Martínez-Alonso, A.; Tascón, J.M.D. Composition of gases released during olive stones pyrolysis. J. Anal. Appl. Pyrolysis 2002, 65, 313-322. [CrossRef]

24. Liu, Q.; Wang, S.; Zheng, Y.; Luo, Z.; Cen, K. Mechanism study of wood lignin pyrolysis by using TG-FTIR analysis. J. Anal. Appl. Pyrolysis 2008, 82, 170-177. [CrossRef]

25. Uddin, M.A.; Tsuda, H.; Wu, S.; Sasaoka, E. Catalytic decomposition of biomass tars with iron oxide catalysts. Fuel 2008, 87, 451-459.

26. Yu, Y.; Li, X.; Su, L.; Zhang, Y.; Wang, Y.; Zhang, H. The role of shape selectivity in catalytic fast pyrolysis of lignin with zeolite catalysts. Appl. Catal. A Gen. 2012, 447-448, 115-123. [CrossRef]

27. Ben, H.; Ragauskas, A.J. Pyrolysis of Kraft Lignin with Additives. Energy Fuels 2011, 25, 4662-4668. [CrossRef]

28. Ma, Z.; Custodis, V.; Van Bokhoven, J.A. Selective deoxygenation of lignin during catalytic fast pyrolysis. Catal. Sci. Technol. 2014, 4, 766. [CrossRef]

29. Lv, G.; Wu, S.; Lou, R.; Yang, Q. Analytical Pyrolysis Characteristics of Enzymatic/Mild Acidolysis Lignin from sugarcane bagasse. Cellul. Chem. Technol. 2010, 44, 335-343.

30. Wang, S.; Wang, K.; Liu, Q.; Gu, Y.; Luo, Z.; Cen, K.; Fransson, T. Comparison of the pyrolysis behavior of lignins from different tree species. Biotechnol. Adv. 2009, 27, 562-567. [CrossRef]

31. Guo, D.L.; Wu, S.B.; Liu, B.; Yin, X.L.; Yang, Q. Catalytic effects of $\mathrm{NaOH}$ and $\mathrm{Na}_{2} \mathrm{CO}_{3}$ additives on alkali lignin pyrolysis and gasification. Appl. Energy 2012, 95, 22-30. [CrossRef]

32. Hosoya, T.; Kawamoto, H.; Saka, S. Secondary reactions of lignin-derived primary tar components. J. Anal. Appl. Pyrolysis 2008, 83, 78-87. [CrossRef]

33. Geng, J.; Wang, W.L.; Yu, Y.X.; Chang, J.M.; Cai, L.P.; Shi, S.Q. Adding Nickel Formate in Alkali Lignin to Increase Contents of Alkylphenols and Aromatics during Fast Pyrolysis. Bioresour. Technol. 2017, 227, 1-6. [CrossRef] [PubMed]

34. Cui, Y.; Chang, J.M.; Wang, W.L.; Li, B.; Ren, X.Y. Preparation of activated carbon using bio-oil phenol-formaldehyde resin. Bioresources 2015, 10, 3865-3873. [CrossRef]

(C) 2019 by the authors. Licensee MDPI, Basel, Switzerland. This article is an open access article distributed under the terms and conditions of the Creative Commons Attribution (CC BY) license (http://creativecommons.org/licenses/by/4.0/). 